\title{
IDENTIFIKASI JAHE - JAHEAN (ZINGIBERACEAE) DI KAWASAN HUTAN LINDUNG GUNUNG BAWANG KABUPATEN BENGKAYANG KALIMANTAN BARAT
}

\author{
(Identification of Gingers Species (Zingiberaceae) in Gunung Bawang Protected Forest \\ Bengkayang Regency Kalimantan Barat)
}

\author{
Bendril Sepito, Togar Fernando M, Siti Masitoh Kartikawati \\ Fakultas Kehutanan Universitas Tanjungpura Pontianak, Jl. Daya Nasional Pontianak 78124 \\ E-mail: bendril28@gmail.com
}

\begin{abstract}
Family Zingiberaceae is one of flowing plant known by the community as ginger. Many Zingiberaceae found in tropical forest areas, especially Indo-Malaya. There are around $50 \%$ genus growth in lowland forest more than 2000 masl. The purpose of this study was to identify the ginger species (Zingirberaceae) of protected forest in Gunung Bawang Bengkayang Regency West Kalimantan. The method used in this research was survey purposive determination starting point. The survey consisted of 5 transect that length at $200 \mathrm{~m}$. The results showed that gingers species found in Gunung Bawang was 17 gingers species, that were classified into 6 Genus. Globba propingua Ridl was found with the highest number of species. Overall, the research showed that the Gunung Bawang is in a good state and to be maintained.
\end{abstract}

Keyword: Gunung Bawang, Gingers, Protected forest, Zingiberaceae

\section{PENDAHULUAN}

Zingiberaceae adalah salah satu family dari suku tumbuhan berbunga yang biasa di kenal oleh masyarakat sebagai jahe-jahean. Family Zingiberaceae banyak ditemukan pada kawasan hutan tropis, terutama IndoMalaya. Family Zingiberaceae ini belum diketahui secara pasti berapa pasti jumlah jenisnya, Menurut Pandey (2003), terdapat sekitar 50 persen dari total genera famili Zingiberaceae ini ditemukan di hutan tropis dan dapat hidup dari dataran rendah sampai pada ketinggian lebih dari 2000 MDPL terutama pada daerah dengan curah hujan yang tinggi. Sejauh ini daerah yang kaya akan jenis-jenis Zingiberaceae adalah wilayah
Indonesia, Malaysia, Brunei, Singapura, Thailand, Filipina dan Papua.

Selanjutnya dilakukan oleh Lamb (2013) yang mendeskripsikan bahwa di Borneo atau Kalimantan sendiri famili Zingiberaceae memiliki 19 genus dengan jumlah 250 jenis dan masih banyak yang belum dideskripsikan sebagai jenis baru. Dibagian utara Borneo telah banyak dilakukan penelitian mengenai famili ini, seperti penelitian yang dilakukan oleh Gobilik dan Mashitah (2005) yang mendata jenis-jenis Zingiberaceae.

Zingiberaceae yang paling banyak dimanfaatkan terdapat pada genera Alpinia, Amomum, Curcuma, Zingiber, Boesenbergia, Kaempferia, Elettaria, Elettariopsis, Etlingera dan Hedychium. 
Sekitar 20 jenis Zingiberaceae yang telah dibudidayakan untuk digunakan sebagai bumbu masakan, pewangi, tanaman hias dan baru-baru ini sebagai bunga potong yaitu Etlingera. Beberapa jenis Curcuma dapat digunakan untuk mengobati gigitan ular dan anti tumor. Kandungan minyak atsiri dalam Zingiber dapat dimanfaatkan sebagai obat dan memiliki aroma yang khas (Larsen, 1999)

Kawasan hutan lindung Gunung Bawang terletak di desa Suka Bangun, Kecamatan Sungai Betung, Kabupaten Bengkayang, Provinsi Kalimantan Barat, berdasarkan wilayah adminitrasi pemerintah yang memiliki luas 961,65Ha. Hutan Lindung Gunung Bawang, memiliki potensi keanekaragaman flora yang sangat tinggi, keberadaan hutan lindung ini menjadi hal yang penting terutama terkait fungsi konservasi dan penyangga tata hidrologi kawasan disekitarnya. Penelitian ini bertujuan untuk mengidentifikasi jenis jahe-jahean liar family Zingiberaceae yang ada di Hutan Lindung Gunung Bawang Kabupaten Bengkayang. Adapun manfaat dari penelitian ini adaah memberikan informasi mengenai jenis tumbuhan jahe-jahean liar (Zingiberaceae) yang ada di Kawasan Hutan Lindung Gunung Bawang.

\section{METODE PENELITIAN}

Penelitian ini dilaksanakan di Hutan Lindung Gunung Bawang, Kabupaten Bengkayang, Kalimantan Barat, dengan waktu pelaksanaan penelitian 23-30 Mei 2018 efektif dilapangan, menggunakan metode eksplorasi dengan jalur yang dilakukan dengan cara jelajah, penempatan jalur berdasarkan perjumpaan objek penelitian, yaitu menjelajahi setiap sudut suatu lokasi yang dapat mewakili tipe-tipe ekosistem atau pun vegetasi di kawasan yang diteliti (Rugayah, 2004). Jumlah jalur yang dibuat sebanyak 5 jalur dengan panjang 200 meter. Setiap jenis yang dikoleksi terlebih dahulu diberi nomor koleksi dan dicatat informasi lapangannya. Pengambilan contoh herbarium pada lokasi penelitian hanya dilakukan sekali untuk setiap jenisnya. Apabila ditemukan jenis yang sama maka hanya dilakukan pendataan pada jenis tersebut. Adapun alat dan bahan yang digunakan dalam penelitian ini adalah kamera, peta lokasi, kain hitam, ATK, GPS, pita ukur, tally sheet, peralatan pembuatan herbarium dan buku identifikasi.

Pengumpulan data dilapangan berupa nama lokal, tinggi, ciri-ciri morfologi vegetative maupun generative (jika tersedia), nama ilmiah (dapat langsung dicatat jika diketahui), habitat, ketinggian tempat, titik koordinat lokasi, nomor koleksi, tanggal pengamatan, dan contoh koleksi spesimen berupa daun, buah, dan bunga (jika tersedia). Sesuai dengan tujuan penelitian, analisis data yang digunakan adalah analisis kualitatif. Analisis dilakukan dengan cara mendeskripsikan ciri-ciri morfologi (generatif maupun vegetatif) secara detail pada semua jenis jahe yang ditemukan disetiap jalur penelitian. Semua jenis Jahe tersebut dicatat kedalam tally sheet pengamatan, kemudian dianalisis lebih lanjut dengan melakukan identifikasi jenis pohon.

HASIL DAN PEMBAHASAN 
Hasil pengamatan di lapangan pada 5 jalur jelajah dengan arah yang bervariasi pada setiap jalurnya yaitu jalur A dengan tipe habitat sekunder muda bekas ladang masyarakat, jalur B ialah jalur tepi sungai 1 dengan kondisi habitat yang lembab, jalur $\mathrm{C}$ ialah jalur yang mempunyai habitat yang bervariasi karna mengikuti kontur, jalur D berada pada tepi sungai 2 sedangkan jalur $E$ ialah jalur yang ada pada ketinggian $600 \mathrm{mdpl}$, Setelah melalui proses identifikasi ditemukan 17 jenis Zingiberaceae yang tergolong ke dalam 6 marga (genus) berbeda. Pada jalur pengamatan A ditemukan 7 jenis dari 5 genus yang berbeda, jalur pengamtan $\mathrm{B}$ ditemukan 4 jenis dari 4 genus berbeda, jalur pengamatan $\mathrm{C}$ terdapat 8 jenis dari 5 genus, Jalur pengamatan D ditemukan 6 jenis dari 3 genus yang beda dan jalur $\mathrm{E}$ ditemukan 5 jenis dari 3 genus yang beda. Hasil selengkapanya dapat dilihat pada Tabel 1.

Tabel 1. Hasil Identifikasi Jenis Zingiberaceae Yang Ditemukan Pada Semua Jalur Pengamatan (Results of Identification of Types of Zingiberaceae Found on All Observation Pathways)

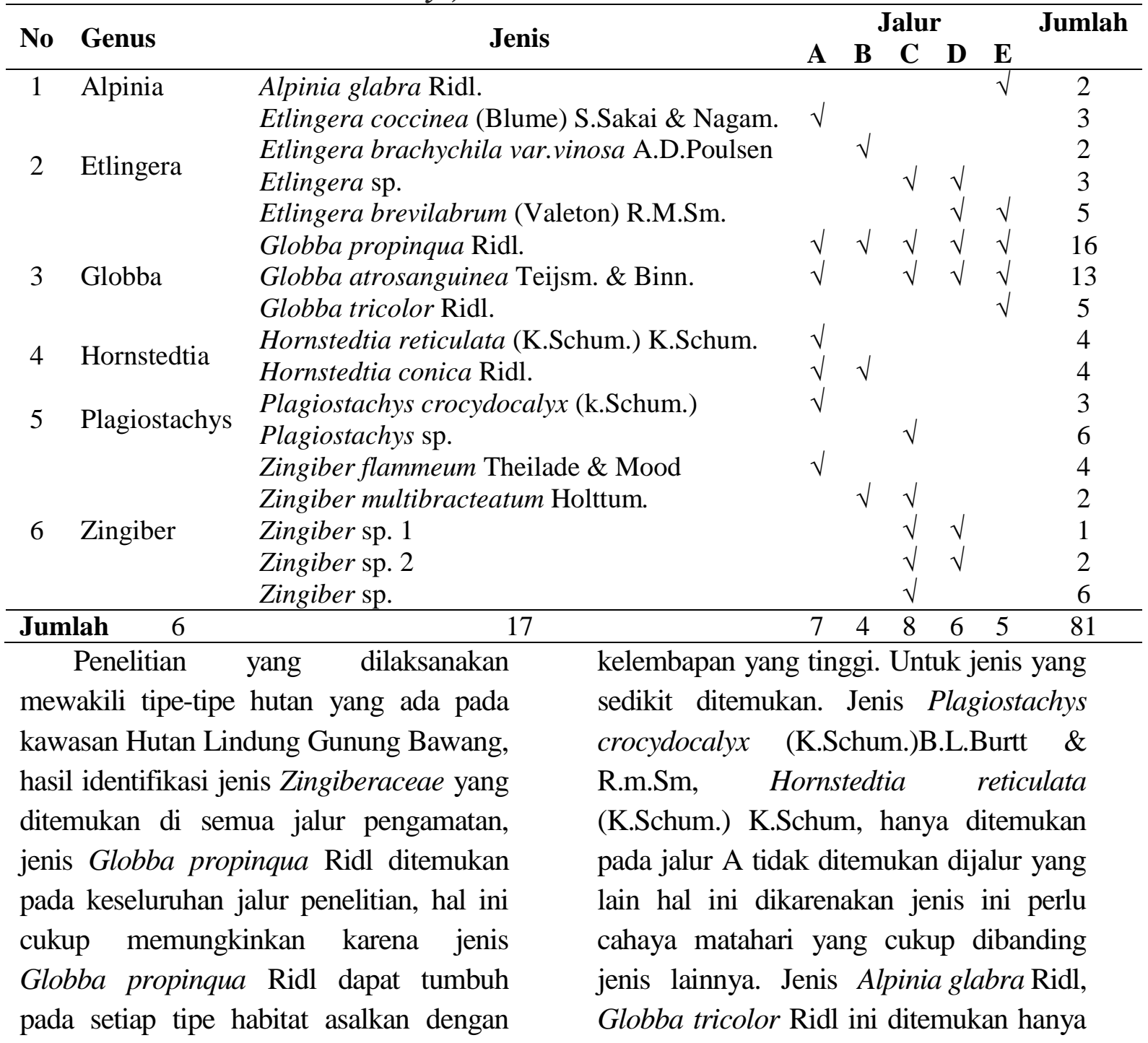


pada jalur E dengan ketinggian diatas 600 mdpl.

Zingiberaceae yang telah ditemukan dikawasan hutan lindung Gunung Bawang berdasarkan pada Tabel 1 sebanding dengan penelitian Zingiberaceae di hutan lindung Gunung Ambawang Kubu Raya oleh suryanto (2015) yang dimana ditemukan 7 genus dari 10 jenis yang ada dengan jumlah individu sebanyak 39. Perbedaan jumlah zingiberaceae yang diperoleh di dua lokasi penelitian yang berbeda tersebut salah satunya disebabkan oleh perbedaan faktor fisik lingkungan, yaitu letak topografi dua kawasan. Lokasi kawasan Hutan Lindung Gunung Bawang merupakan kawasan yang termasuk ke dalam hutan pegunungan bawah sampai dengan 1456 mdpl. Hal ini sesuai dengan pendapat Padley (2003) yang menyatakan bahwa zingiberaceae dapat hidup dari dataran rendah sampai ketinggian 2000 mdpl terutama didaerah dengan cuarah hujan yang tinggi.

Berdasarkan hasil penelitian terdapat 5 jenis dari total 17 jenis yang ditemukan tidak teridentifikasi sampai ketingkat jenis. Hal ini dikarenakan beberapa jenis tidak mempunyai data yang lengkap seperti bunga dan buah dari spesies tersebut. Holtum (1950) menyatakan kebanyakan kasus pada penelitian jarang menemukan bunga Zingiber sehingga data yang diperoleh kurang lengkap, hal ini dikarenakan bunga tersebut berumur pendek, bunga mekar pada pagi hari dan setelah itu menutup dalam beberapa jam, dan bunga tersebut dapat mengalami kerusakan, Sama halnya dengan genus Plagiostachys beberapa hal yang membuat genus ini tidak teridentifikasi karena hampir semua genus ini memiliki bunga yang sama dengan jenis lainya.

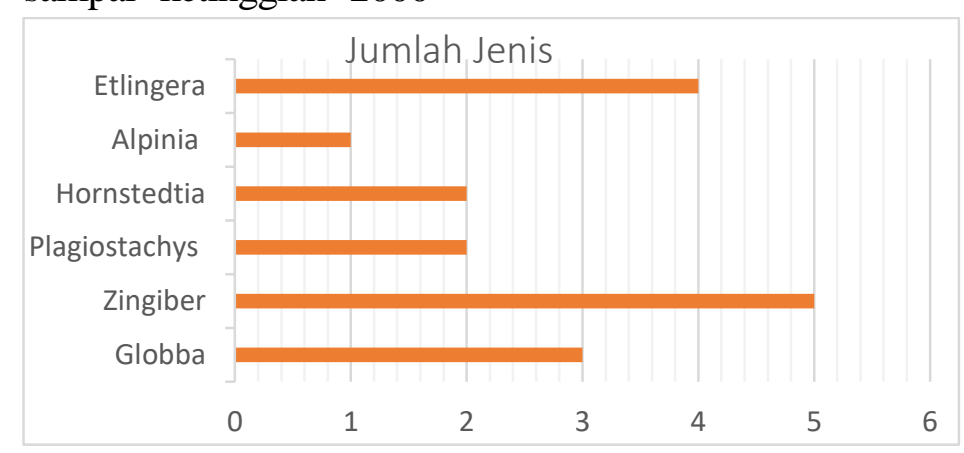

Gambar 1. Grafik genus yang ditemukan dengan jumlah jenis terbanyak (Chart of genus found with the highest number of species)

Jumlah genus yang ditemukan pada lokasi penelitian sebanyak 6 genus, genus yang ditemukan pada semua jalur penelitian ialah genus Globba sedangkan genus Alpinia ditemukan hanya pada jalur E. Genus Hornstedtia ditemukan pada jalur C, A dan pada jalur B. Genus Zingiber ditemukan pada jalur A, B C dan pada jalur D. Genus Etlingera ditemukan pada jalur A dan B, genus Plagiostachys ditemukan pada jalur $\mathrm{A}$ dan jalur $\mathrm{C}$. 


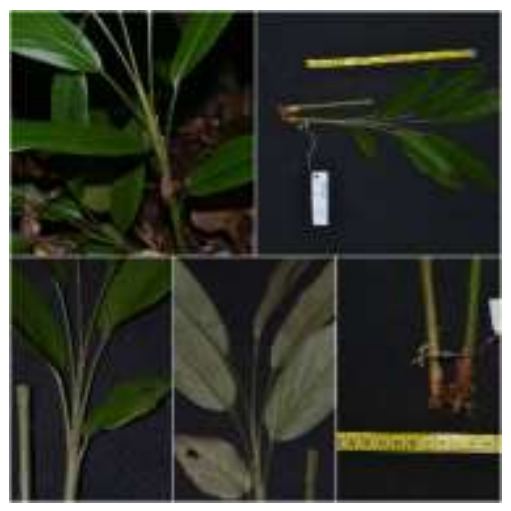

Gambar 2. Alpinia glabra Ridl

Genus Alpinia yang ditemukan pada lokasi penelitian ialah Alpinia glabra Ridl ditemukan pada daerah yang tertutup dan ternaungi dengan intensitas cahaya matahari yang cukup. Menurut Nurainas (2007) genus Alpinia memiliki tempat tumbuh di pinggir sungai dan daerah yang tertutup.

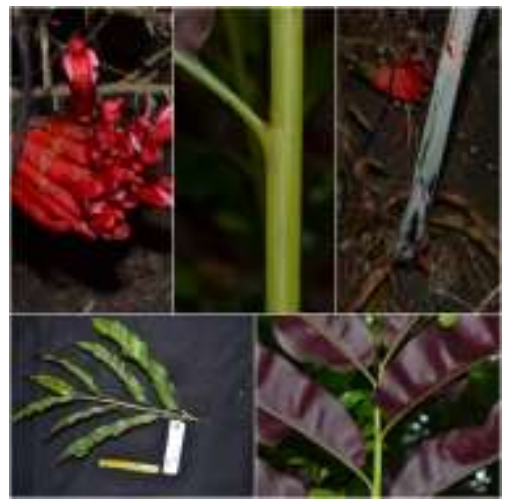

Gambar 3. Etlingera brevilabrum

(Valeton) R.M.Sm.

Genus Etlingera terdiri dari empat jenis yaitu Etlingera brachychila var.vinosa A.D.Poulsen, Etlingera brevilabrum (Valeton) R.M.Sm, Etlingera coccinea (Blume) S.Sakai \& Nagam, dan Etlingera sp dilokasi penelitian pada jalur B ditemukan Etlingera brachychila var.vinosa A.D.Poulsen daerah yang cukup terbuka dengan intensitas cahaya matahari yang tinggi sedangkan Etlingera brevilabrum (Valeton) R.M.Sm yang ditemukan pada jalur E yang memiliki ketinggian diatas 600 MDPL keadaan habitat jenis ini dibawah naungan dan daerah yang tertutup. Etlingera $s p$ yang belum teridentifikasi berada pada jalur A, kurangnya studi tentang keberadaan jenis gingers di Kalimantan menyebabkan jenis ini belum dapat teridentifikasi. Menurut Larsen et al dalam Nurainas \& Yunaidi (2007) menyatakan secara alami Etlingera tumbuh mengelompok di tempat-tempat yang lembab dekat dengan aliran sungai dengan vegetasi yang cukup rapat.

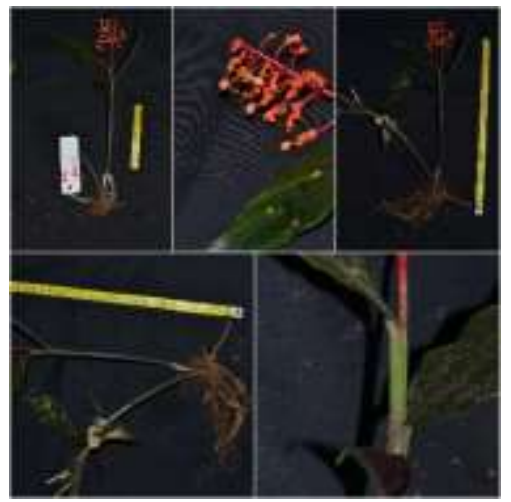

Gambar 4. Globba atrosanguinea Teijsm. \& Binn

Genus Globba ditemukan di lapangan dengan jenis Globba atrosanguinea Teijsm. \& Binn, Globba propinqua Ridl, Globba tricolor Ridl, genus ini ditemukan pada daerah-daerah yang lembab disekitar aliran sungai dan tumbuh ditengah berbatuan kecil pada bibir sungai. Globba tricolor Ridl dijumpai pada level ketinggian $700 \mathrm{mdpl}$ dengan intensitas cahaya matahari yang cukup dan tumbuhnya juga pada berbatuan berlumut di jalur pendakian. Menurut Van valkenburg \& Bunyapraphatsara dalam hamzah (2016), genus Globba dapat tumbuh dari daerah yang cukup tinggi, tetapi jenis ini lebih banyak ditemukan 
didaerah yang cukup ternaungi dan disepanjang daerah aliran sungai. Globba merupakan jenis yang meiliki penyebaran yang luas, mulai dari timur Himalaya dan Selatan China sampai ke Malaysia, semua jenis Globba ini hidup pada daerah yang teduh.

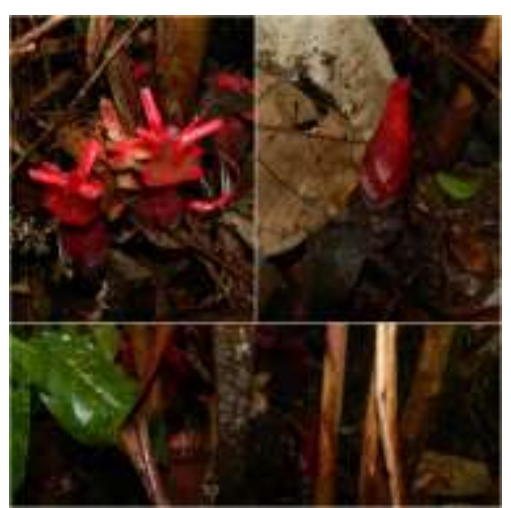

Gambar 5. Hornstedtia reticulata

(K.Schum.) K.Schum

Genus Hornstedtia yang ditemukan yaitu Hornstedtia conica Ridl dan Hornstedtia reticulata (K.Schum.) K.Schum dijumpai pada lokasi penelitian didaerah-daerah yang terbuka dengan intensitas cahaya yang cukup tinggi, jenis ini juga sering djumpai dalam keadaan rusak karena dimakan oleh hewan. Hamzah (2016) ciri khas dari genus Hornstedtia yaitu pembungaan yang berbetuk kumparan dilapisi oleh bractea yang kompak menjadi pembeda dengan genus lainnya.

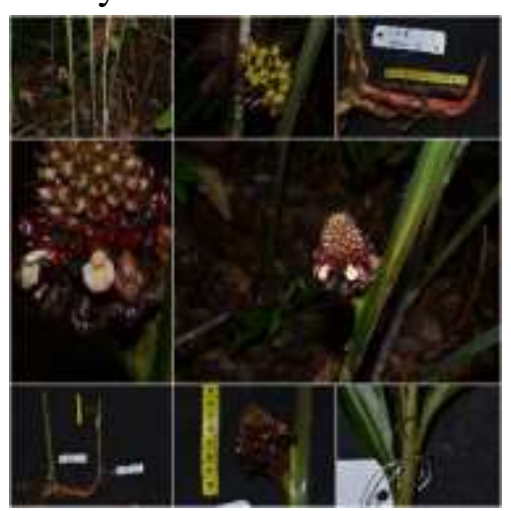

Gambar 6. Plagiosthacys sp

Genus plagiosthacys yang diperoleh yaitu Plagiostachys crocydocalyx, Plagiosthacys sp, jenis ini merupakan jenis ke tiga yang belum teridentifikasi sampai ke tingkat spesies. Pada saat penelitian untuk jenis ini dijumpai pada daerah aliran sungai dengan cahaya matahari cukup. Karakter umum untuk membedakan genus ini yaitu bractea yang mendukung perbungaan keluar atau muncul langsung dari batang semu. Zingiberaceae dapat hidup dan berkembang melalui organ vegetatif yaitu dengan adanya rhizom. Dumbois \& Ellenberg (1974) menyatakan jenis yang memperbanyak diri dengan biji lebih luas penyebarannya jika dibandingkan dengan jenis tumbuhan yang alat reproduksinya menggunakan organ vegetatif.

Genus Zingiber ditemukan lima jenis yaitu Zingiber multibracteatum Holtum, Zingiber sp, Zingiber sp.1, Zingiber sp.2, Zingiber flammeum Theilade \& Mood. ini merupakan beberapa jenis yang ditemukan dan belum teridentifikasi sampai ke tingkat spesies dikarenakan pada saat penelitian tidak dijumpai bunga dari jenis ini, tetapi bractea yang dimiliki oleh jenis ini merupakan ciri khas dari genus Zingiber. Kebanyakan kasus para peneliti jarang menemukan bunga dari Zingiber sehingga data yang diperoleh tidak lengkap. Hal ini dikarenakan bunga Zingiber umurnya pendek dan bunga mekar pada pagi hari setelah itu menutup dalam beberapa jam. Selain itu, bunga Zingiber juga cepat mengalami kerusakan sehingga memungkinkan penyebaran Zingiber jarang terjadi (Holtum, 1950). 


\section{Kesimpulan}

Berdasarkan penelitian identifikasi jenis jahe-jahean liar (Zingiberaceae) di kawasan hutan Lindung Gunung Bawang kabupaten Bengkayang Kalimantan Barat disimpulkan:

1. Jenis yang ditemukan tergolong dalam 6 genus dengan total 17 spesies yaitu: Globba propinqua Ridl, Zingiber flammeum Theilade \& Mood, Plagiostachys crocydocalyx (k.Schum.) B.L.Burtt \& R.M.Sm, Hornstedtia reticulata (K.Schum.) K.Schum, Globba atrosanguinea Teijsm. \& Binn, Hornstedtia conica Ridl, Etlingera coccinea (Blume) S.Sakai \& Nagam, Etlingera brachychila var.vinosa A.D.Poulsen, Zingiber multibracteatum Holttum, Plagiostachys sp, Etlingera sp, Zingiber sp. 1, Zingiber sp. 2, Zingiber sp, Etlingera brevilabrum (Valeton)

R.M.Sm,

Alpinia glabra Ridl, Globba tricolor Ridl.

\section{Saran}

Tersedianya data mengenai jenis jahejahean liar dikawasan Hutan Lindung Gunung Bawang Kabupaten Bengkayang diharapkan dapat dijadikan referensi untuk dilakukan penelitian-penelitian lanjutan yang lebih luas tentang keanekaragaman jenis dan kajian kandungan kimia, terutama minyak atsiri yang terdapat pada Rimpang / Rhizom sehingga jenis-jenis yang ditemukan dapat diketahui potensinya dan dapat dimanfaatkan.

\section{DAFTAR PUSTAKA}

Anonim. 2016. Kecamatan Sui Betung Dalam

Angka.(http//bengkayangkab.bps.go. id di Akses tanggal 20 Juni 2018).

Anonim. 2000. Surat Keputusan Menteri Kehutanan dan Perkebunan Nomor 259/Kpts-II/2000, tentang penunjukan Kawasan Hutan dan Perairan. Kalimantan Barat. Pontianak.

Ambriansyah. 2010. Teknik Pengenalan Jenis dan Pembuatan Herbarium. Samboja. Kalimantan Timur.

Gobbilik J, Mashitah MY. 2005. Zingiberaceae and Costaceae of the Trus Madi Range. Jurnal Of Trofical Biologi and Conservation 1(4): 7993

Lamb A. 2013. A Guide to Gingers of Borneo. Kota Kinabalu: Natural History Publications (Borneo).

Larsen. 1999. Gingers of Penisular Malaysia and Singapura. Kota Kinabalu: Natural History Publicasions (Borneo).

Nurainas, Yunaidi. 2006. Panduan lapangan Jahe-Jahean Liar di Taman Nasional Siberut.Padang: Garista.

Poulsen AD. 2007. A Pocket Guide of Sarawak. Kota kinabalu Natural History Publication (Borneo).

Poulsen AD. 2006. Etlingera of Borneo. Kota kinabalu Natural History Publication (Borneo).

Suriyanto I. 2015. Identifikasi Jenis JaheJahean Liar (Zingiberaceae) dikawasan Hutan Lindung Gunung Ambawang Kecamatan Kubu Kabupaten Kuburaya. Jurnal Hutan Lestari 4(1): 65-71. 